\title{
REFLECTIONS ON THE MAIN SYNTACTIC PROCESSES OF THEMATIZATION IN ENGLISH IN ALAN PATON'S PLAY SPONONO
}

\author{
María Martínez Lirola* \\ University of Alicante and Research Fellow, Department of Linguistics, \\ University of South Africa
}

\begin{abstract}
This paper will analyse the main marked syntactic structures of thematization in English in the play Sponono, written by Alan Paton in 1965. The analysis will point out that due to the use of these thematization processes in the play, i.e. cleft sentence, pseudo-cleft sentence, topicalization and passive, the author emphasizes the feelings and thoughts of the main characters in the play.

The analysis will also make clear that the examples of the structures under analysis are used in situations of climax and the main reason for the author to use them is to highlight the social situation that surrounds the play: the apartheid period in South Africa. The paper will discuss how Alan Paton creates a social reality throughout the recurrent use of these processes. In the same way, these syntactic processes contribute to the vividness of the play.

The social situation of this period in South Africa has very particular characteristics that the author tries to point out and reproduce with the processes of thematization he uses recurrently during the whole play. The analysis of the corpus following the theory of Systemic Functional Grammar will be helpful to understand the relationships between language and culture and language and situation.
\end{abstract}

\section{RESUMEN}

El marco teórico de este artículo es la teoría funcional denominada Gramática Sistémica Funcional cuya figura principal es Michael Halliday por dos razones principales: la importancia del contexto para el análisis de los principales procesos sintácticos de tematización en inglés y porque estudia la lengua en relación con la sociedad y analiza las principales razones para elegir entre unas formas lingüísticas u otras, hecho que siempre está determinado por la función que esas formas lingüísticas tienen en la sociedad. Esta teoría analiza auténticos productos de interacción social (textos).

\footnotetext{
*maria.lirola@ua.es
} 
En lugar de haber elegido ejemplos independientes de un corpus computacional, hemos decidido analizar con detalle las principales estructuras de tematización en inglés en la obra de teatro Sponono, escrita por el escritor sudafricano Alan Paton en 1965. Debido al uso de los principales procesos de tematización en la obra de teatro- oración hendida, oración semi-hendida inversa, topicalización y pasiva- podemos percibir los pensamientos y sentimientos de los principales personajes de la obra. También podemos observar que estas estructuras se usan en situaciones de climax.

\section{INTRODUCTION}

This article is within the framework of Systemic Functional Linguistics for the two main purposes of the article: to highlight the importance of context for the analysis of the main syntactic processes of thematization in English. In addition, language will be studied in relation to society, and this research will analyse the main reasons for choosing between some linguistic forms or others, which is always determined for the function that those linguistic forms have in society (Fernández Martínez, 2011; Matthiessen et al., 2010; Martin and Rose, 2007; Alexander, 2008; Teubert, 2010). This theory analyses authentic products of social interaction (texts).

In this sense, we agree with Halliday et al. (1964: 52) in that "the relationships between medium and linguistic structure, like those between contextual factors and medium, are functionally motivated". From this we can deduce that "there is a probabilistic relationship between types of situation and types of linguistic structure".

In a functional grammar, the interpretation of language is understood as a system of meanings with the forms that those meanings express (Halliday, 1994:xiii-xiv). In this sense, a functional grammar is always connected with semantics, in Halliday's words (1994:xx): "The fact that this is a 'functional' grammar means that it is based on meaning; but the fact that is a 'grammar' means that it is an interpretation of linguistic forms."

Following Couture (1991:261), there are three premises which govern the linguistic laws or patterns established by functional language theory: language constructs social harmony, language organizes space and time and language polarizes reality. In her view, through these three orientations, conventional meanings, structures and ideologies are functionally validated.

Instead of having chosen independent examples coming from a computational corpus, it was decided to analyse in detail these structures in the play Sponono, written by the South African writer Alan Paton in 1965. The play is located in a reformatory for boys in Victoriatown, a suburb of Johannesburg. Sponono, the protagonist, is one of the boys in the reformatory that is always between what is right and what is wrong. Having selected the corpus, Biber et al.'s ideas (1998:4) about the essential characteristics of corpus-based analysis were followed: 
"- it is empirical, analyzing the actual patterns of use in natural texts; -it utilizes a large and principled collection of natural texts, known as a "corpus" as the basis for analysis;

-it makes extensive use of computers for analysis, using both automatic and interactive techniques;

-it depends on both quantitative and qualitative analytical techniques."

Due to the use of the main thematization processes in the play- cleft sentences, reversed- pseudo cleft sentences, topicatization, and passive voicethe author points out the feelings and thoughts of the main characters in Sponono. These structures are also used in situations of climax, as I will explain in the following paragraphs.

\section{ANALYSIS OF THE MAIN STRUCTURES OF THEMATIZATION IN SPONONO}

\subsection{2 .1 Analysis of cleft sentences}

Jespersen (1909-1949:Vol. VII:147-148) defines cleft sentences in the following way: "A cleaving of a sentence by means of it is (often followed by a relative pronoun or connective) serves to single out one particular element of the sentence and very often, by directing attention to it and bringing it, as it were, into focus, to mark a contrast."

In Systemic Functional Linguistics, the term used by Halliday and Matthiessen (2004: 95) to refer to this syntactic structure is "predicated theme", because the elements found at the beginning of the structure are introduced by the predicative formula "it +be". After that, there is a nominal or adverbial group that receives emphasis. Grzegorek (1984:70) points out the following ideas about the use of cleft sentences:

"Generally cleft constructions are used whenever the speaker wants to give special prominence to the new, most prominent information. He may also choose to put heavy stress on the information focus in its regular position. Clefts, however, are preferred, especially in written English where stress cannot be marked."

After the definition of the structure, it is essential to analyse the cleft sentence: this syntactic structure is introduced by a pronoun it functioning as subject, which is at the same time a theme without any meaning. It is followed by the verb $b e$, and the real theme of the sentence, i.e., the emphasized element and the relative clause.

According to the division of the structure in terms of theme and rheme, Halliday and Matthiessen (2004: 97) point out that it can be done in two 


\section{VOLUME 5}

different ways: the first one represents the local thematic structure of the two sentences that appear in this construction. The second one points out the thematic structure of the whole sentence, as we can see in the following example:

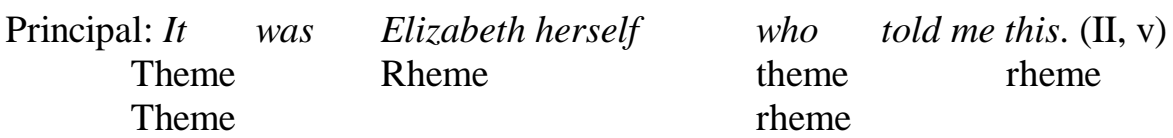

With regard to the form of the emphasized element, it is a nominal group in all the examples of the corpus:

Sponono: It was my eye that was hurt, not yours. (I, v)

Mrs. Makatini: It was our money that was stolen. (II, i)

Sometimes this nominal group is a personal pronoun or a proper noun as we can observe in the examples that follow:

Elizabeth: It's you who are making him sick. (II, iii)

Principal: It was Elizabeth herself who told me this. (II, v)

This emphasized element is highlighted even more with a reflexive pronoun in the following example:

Principal: It was Elizabeth herself who told me this. (II, v)

As regards the emphasized element's function, it fulfils the function of subject, as it happens in the examples that already offered, except in the following one in which it fulfils the function of object:

Sponono: You see, he knows the words. It was the meanings he didn't know. (III)

In relation to the relative pronoun that introduces the second part of the structure, it is evident that in the previous examples it is that or who, and there are also examples without any pronoun.

Cleft sentences are mainly used to contrast and to emphasize. In the following example, Sponono points out his surprise and emotion with a cleft sentence when he knows that Elizabeth is going to get married to Spike:

\section{Sponono: So it's you two that are getting married! (I, ii)}

In this example, Mrs Makatini asks the director to forgive Sponono after he has stolen her and her husband: 
Mr. Makatini: We forgive him, meneer.

Mrs. Makatini: It was our money that was stolen. (II, i)

In the following example, Elizabeth emphasizes with this structure that Walter is a bad influence for Spike:

Walter: You know, that Billy Boy of yours is sick. He ought to see a doctor.

Elizabeth: It's you who are making him sick. (II, iii)

The next example points out the importance of Sponono's answer when he is asked by the principal of the reformatory, because Elizabeth had told the principal that Sponono had asked her to postpone the marriage:

Principal: Is it true that you advised Spike and Elizabeth to postpone their wedding?

Think carefully before you answer. It was Elizabeth herself who told me this. (II, v)

Sponono: You see, he knows the words. It was the meanings he didn't know. (III)

In the following example there is a clear contrast because Sponono uses the negative adverb 'not', and first and second person references ('my' and 'yours'):

Sponono: It was my eye that was hurt, not yours. (I, v)

As Halliday and Matthiessen (2004: 96) point out "the predicated Theme structure is frequently associated with an explicit formulation of contrast; it was not..., it was..., who/which...; for example [...]: And, say the authors, it was Mary Magdalen, not Mary the Mother of Jesus, who has been the real, if secret, object of Mariolatry cults down the ages."

Apart from cleft sentences, this paper will refer to other syntactic structures used by the author as a way of controlling the sentence (Martínez Lirola, 2009). Furthermore, these structures communicate the message in a way that shows the author's ideology (Martínez Lirola, 2007, 2008, 2011), and adds vividness to the context in which Paton writes and to the linguistic forms he uses.

\subsection{Analysis of reversed-pseudo cleft sentences}

Halliday and Matthiessen (2004: 70) refer to this structure as "marked thematic equative". In this version of the pseudo-cleft sentence, we can find the following wh-forms: what, why, where, how and when. The most 
common are what and why, as we will see when we analyse our examples. Quirk et al. (1985:1388) declare that "clauses with who, where, and when are sometimes acceptable but mainly when the wh- clause is subject complement":

\section{Here is where the accident took place.}

(In) Autumn is when the countryside is most beautiful.

(?) The police chief was who I meant.

There are several examples of reversed-pseudo clefts in the play under analysis. We find this structure when there is a nominal relative clause at the end of the complex sentence functioning as subject complement, and the emphasis is placed on the subject. It is a $\mathrm{SVC}^{1}$ structure with a nominal relative clause as subject complement. As regards the analysis of the structure as theme and rheme, the following division can be established:

$\begin{array}{rll}\text { Mrs. Makatini: That } & \text { is } & \text { where they stay. (I, vi) } \\ \text { Theme } & \text { transition } & \text { Rheme }\end{array}$

The reversed-pseudo cleft sentence fulfils the principles of "end-focus" and "end-weight" (Martínez Lirola, 2002, 2009). Reversed-pseudo cleft sentences are unmarked from the thematic point of view, because they express the theme with the subject, which is normal in declarative sentences. In these structures, it is the identifier element instead of the identified that tends to be thematic and receive emphasis. The identified element is rhematic.

In the theme, there are normally pronouns or demonstratives that make reference to something that has been previously said; in the majority of the examples of Sponono we find that as identifier; it appears in just one example:

Spike: That's what Sponono says too. (II, ii)

Mrs. Makatini: Yes, that is what I thought. (III)

Spike: It's what I dreamed. (I, ii)

After the pronoun or the demonstrative, we find the copulative verb in present. Afterwards, there is a nominal relative clause (identified element), introduced by what in the majority of the examples as we can see in the examples already mentioned, but it can also be introduced by why:

Walter: That is why I got permission to go to the hospital, so that I could ask Sponono to forgive me. (I, v)

\footnotetext{
${ }^{1}$ Subject Verb Complement.
} 
Principal: Now that is not the reason why I am not punishing you. I am punishing you because I still hope you will learn that you cannot strike whenever you want to. (I, v)

It is evident that in these two examples, the demonstrative found in the first part of the structure has cataphoric reference. In this last example, there is also a clear contrast. The second example of the two that we have just offered is the only one that is negative. For this reason, it is clear that it shows a clear contrast between the reversed-pseudo cleft and the sentence following it.

In other examples there are the wh-forms where and how. In the second example, as in the majority that appear in the text, the example has anaphoric reference.

Mrs. Makatini: That's where they stay. (I, vi)

Mr. Mabaso: Principal, that's how he was seen last month in Victoriatown. Remember I drew your attention to it? (II, v)

With regards to the function of the structure, after the analysis of the examples, it is obvious that it is mainly used to emphasize; the following example emphasizes a very good attribute of Sponono:

Sponono: Did you ever think of me as a protector of the small kids? Well, that's what I am. The smallest of the small kids is Ha'penny, and I look after him. (I, ii)

The next example points out the mutual love between Spike and Elizabeth before their wedding:

Spike: If it weren't for you, Elizabeth, what would have become of me? Elizabeth: That's what I'm for.

That's what I'm promising tomorrow. To love and to comfort and to keep, not only when you are well, but when you are sick too. (II, ii)

In the following example, it is emphasized the way in which Spike was seen:

Walter: Behing the boxes in the Games Room.

Mr. Mabaso: Principal, that's how he was seen last month in Victoriatown. Remember I drew your attention to it? (II, v) 


\subsection{Analysis of topicalization}

Quirk et al. (1985:1377) define topicalization in the following way: "Fronting is the term we apply to the achievement of marked theme by moving into initial position an item which is otherwise unusual there." The definition offered by Grzegorek (1984:74) is also very clear: "Thematization is a syntactic process whose purpose is to adjust the sentence structure of a given utterance to the requirements of the speech situation in which this utterance is used."

Prince (1984:217) points out that topicalization has the following function: "[...] $\mathrm{TOP}^{2}$ marks the entity represented by the NP as being either already evoked ${ }^{3}$ in the discourse or else in a salient set relation ${ }^{4}$ to something already evoked in or inferable from the discourse."

Topicalization is the term used to speak about a marked theme by putting at the beginning of the sentence a part of the message that is not usual in that position. The examples of topicalization that found in the play are adverbials and prepositional phrases. Despite this, this syntactic structure also appears with nominal, verbal, and adjectival phrases. The function of the examples in our corpus is of circumstantial complement and prepositional complement.

In relation to the analysis of the structure in terms of theme and rheme, it is evident that the theme is always the thematized element, and the rheme is the rest of the structure. See in this example:

Elizabeth: And behind that

Theme is your wedding suit. (II, ii) Rheme

Topicalization fulfils the principles of "end-focus" and end-weight". Sometimes topicalization is used to emphasize, as in these examples in which Sponono is emphasized because he has got his freedom, which means that he is going out of the reformatory:

Principal: Boys, this day another boy in the reformatory receives his freedom.[...]

Sponono: Today I receive my freedom [...]

Principal: Here is your badge of freedom. (I, i)

In the following example, what is emphasized is Sponono's company to point out the importance that the principal has in Sponono's life:

\footnotetext{
${ }^{2}$ Short form used by the author to refer to topicalization.

${ }^{3}$ Italics appear in the original text.

${ }^{4}$ Italics appear in the original text.
} 
Sponono: Mereer, when I am by myself sometimes I go crazy, and then I get into trouble. But with you, I wouldn't go crazy. If I were with you, I wouldn't get into trouble. (I, i)

In the next example, it is emphasized that although Sponono has forgiven Walter, there is another issue between Walter and the director:

Sponono: But meneer, I have forgiven him.

Principal: That was generous of you, Sponono. But your forgiveness is between you and him. Between him and me is another matter. (I, v)

In one of the climatic moments of the play, when Spike is with Elizabeth and somebody knocks on the door, the thematization of the circumstantial element in the stage direction makes the reader perceive the scene with profound emotion:

(Spike wrests the knife from her. He goes quickly to the door. Then with a sudden movement he flings it open. There is no one there. But on the step there is a letter.) (II, ii)

There are other examples in which the intention is to emphasize a place as it happens in the next one, in which Elizabeth pretends to underline the place where the suit of the bridegroom is:

Elizabeth: And behind that is your wedding suit.

And behind that there is nothing. (II, ii)

In the examples in which there are more than one adverbial thematized, the order in which they appear is an adverbial of time followed by an adverbial of place:

Walter: Yesterday, in the Visitors' Room, he couldn't leave her alone. (II, v)

\subsection{Analysis of inversion}

Birner (1996:11) points out that 'the term 'inversion' traditionally refers specifically to the appearance of the logical subject to the right of the main verb and its auxiliaries or, in the case of VP inversion, to the right of the auxiliary be."

Inversion implies a change in the word order of the sentence produced by the thematization of a sentential element. Inversion can be of two types: subject-verb and subject-auxiliary. There is only one example in the play. It is an example of subject-auxiliary inversion, and the author tries to highlight a 


\section{VOLUME 5}

feeling with this example- the fact that Mr. Mabaso and the director are happy due to the good behaviour of Sponono:

Principal: Good morning, Mr Mabaso. You see that. Sponono's first leave, and he came back on the very minute.

Mr. Mabaso: The Principal should feel gratified.

Principal: So should you. Well, did you see Mrs. Maarman? (I, iii)

Regarding the analysis of the structure in terms of theme and rheme, it is evident that the theme is the element that is thematized and causes inversion, and the rheme is the rest of the sentence:

\section{Principal: So should you. \\ Theme Rheme}

Inversion fulfils the principles of "end-focus" and "end-weight". The use of inversion implies subjectivity. It can also be seen as a marker in discourse because it is used to organize the message, and also to make clear that the initial position in the sentence is more relevant for discourse.

\subsection{Analysis of the passive voice}

When there is a transitive verb in a sentence, the passive voice makes possible to postpone the agent subject of the sentence and transform it in the agent complement of the passive construction. At the same time, the passive construction has the property of moving another nominal group, the direct object of the active sentence at the beginning of the sentence.

The passive sentence can have an agent complement or no complement, as Granger (1983:187) points out: "Passive structures are said to be agentful ${ }^{5}$ (A-full) if they contain a prepositional phrase that can be used as the subject of the active structure with which the passive structure alternates; they are agentless (A-less) if that element is merely understood (or covert)."

Nash (1980:140) presents the passive construction as a characteristic of formal discourse: "A further stylistic property of the passive is that it noticeably cools the manner of address - i.e. it is an index of the formal tone".

There are also very few examples of passive sentences in our corpus. In my view, it is very important to underline that we find two aspects in this construction: it is a thematization construction when it has no agent complement; in this way, it is emphasized the result of the action or the

\footnotetext{
${ }^{5}$ Bold appears in the original text.
} 
person who suffers the action, i.e., it is the subject that is emphasized. On the contrary, as a postponement construction, the passive emphasizes the agent when it is present.

There are three examples of passive sentences without agent complement in Sponono. They are thematization examples, which implies that what is emphasized is the result of the action or the person who suffers the action, i.e., the subject. The passive emphasizes the verb if the agent is unknown or if we want to ignore it.

In the following two examples there is no agent complement. Besides, the reference is specific, and linguistic because the agent has been previously mentioned, and the active subject can be understood from the context (Granger, 1983: $308 \mathrm{ff}$.). In the first example the understood subject is 'I', and in the second it is 'Ha'penny':

Principal: Now that is not the reason why I am not punishing you. I am not punishing you because I still hope you will learn that you cannot strike whenever you want to. Therefore you are dismissed with a reprimand. Your belt will be taken away from you, and a softer one will be given to you. (I, v)

Sponono: It's Ha 'penny, mereer.

Principal: He's dying, Sponono. In one day, two days, three days, he'll be gone. (I, v)

In the two previous examples, the passive is used for reasons of tactfulness and delicacy: in the first one, the principal avoids to mention himself related to the punishment, and in the second example he avoids to talk about death.

In this example, following Granger (1983:308 ff.), the referent is non specific and the passive has no agent because it is unknown:

\section{Principal: I'm glad to tell you your money is found. (II, i)}

As it is normal in these constructions, the auxiliary is the verb 'to be', although in some cases is 'to get', but we have no examples in our corpus. As regards the analysis of the sentence in terms of theme and rheme, it is evident that the theme is the first word of the structure, and the rheme is the rest of the construction. The passive fulfils the principles of "end-focus" and "endweight".

\section{CONCLUSIONS}

Profound feelings and emotions are attempted throughout the whole play. An important implication from the functional perspective of language from 
which the examples have been analysed is that language and context are interrelated, in other words, there is a clear relationship between the language used in the play, and that social structure in which it is framed.

Systemic Functional Linguistics has been chosen as a linguistic framework because of our interest in studying how language is used in its context, to be more precise, in the period in which Alan Paton wrote because different elements in the language of the play have been explained by reference to its function in the total linguistic system. Physical properties of texts anchor the text within social circumstances and relations. By giving attention to the physical properties of texts, creativity is located in writing within a framework of concrete social forces.

Word order in English is fixed to a large extent. That is why the use of certain grammatical constructions that break the normal word order is functionally relevant. For example, the use of cleft sentences is a device used to focus on a particular constituent of the sentence.

Since systemic meaning is not independent from context, each of the examples we have presented appears in the appropriate context and in the appropriate discourse situation, which implies that the examples are suitable to each particular discourse situation. The literary text is an authentic text because in it we find the real language in context.

In the examples of the play we have seen how the language chosen by the author is the union through which we can perceive his ideology or world view; apart from this, we can also perceive the social reality that he wants to describe. In this way, the literary text becomes a source of meanings because it shows the relationship between text and social reality.

\section{BIBLIOGRAPHICAL REFERENCES}

Alexander, Richard (2008) Framing Discourse on the Environment. A Critical Discourse Approach. London: Routledge.

Biber, Douglas, Susan Conrad and Randi Reppen (1998) Corpus Linguistics. Investigating Language Structure and Use. Cambridge: Cambridge University Press.

Birner, Betty .J. (1996) The Discourse Function of Inversion in English. London/New York: Garland Publishing.

Couture, Barbara (1991) "Functional Theory, Scientism, and Altruism: A Critique of Functional Linguistics and its Applications to Writing". In E. Ventola (ed.) Functional and Systemic Linguistics: Approaches and Uses. Berlin/Nueva York: Mouton de Gruyter; 259-279.

Fernández Martínez, Dolores (2011) Introducing Discourse Analysis in Class. Cambridge: Cambridge Scholars Publishing.

Granger, Sylviane. (1983) The Be+Past Particle Construction in Spoken English. With Special Emphasis on the Passive. Amsterdam/New York: North Holland.

Grzegorek, Maria. (1984) Thematization in English and Polish. A Study in Word Order. Poznan: UAM. 


\section{REFLECTIONS ON THE MAIN SYNTACTIC PROCESSES OF THEMATIZATION IN \\ ENGLISH IN ALAN PATON'S PLAY SPONONO}

Halliday, Michael Alexander Kirkwood. (1994). An Introduction to Functional Grammar. Second Edition. London: Arnold.

Halliday, Michael Alexander Kirkwood and Christian M.I.M Matthiessen (2004). An Introduction to Functional Grammar. Third Edition. London: Arnold.

Halliday, Michael Alexander Kirkwood, Angus McIntosh and Peter Strevens (1964) The Linguistic Sciences and Language Teaching. London: Longman.

Jespersen, Otto. (1909-1949) A Modern English Grammar on Historical Principles IVII. London/Copenhagen: Allen and Unwin.

Martin, James and David Rose (2007) Working with Discourse. Meaning beyond the Clause. Second edition. London: Continuum.

Martínez Lirola, Maria (2002) A Systemic Functional Study of the Main Processes of Thematization and Postponement in English in the Novels of the South African Writer Alan Paton. University of Jaén: Servicio de Publicaciones de la Universidad [CD-ROM].

Martínez Lirola, Maria (2007) “Exploring the relationship between Paton's ideology and his context". Journal of Literary Theory and Cultural Studies (Licus), 3 (2): 101-112.

Martínez Lirola, Maria (2008) "Exploring Predicated Themes from a Systemic Functional Point of View in Alan Paton's Novels". Journal of Literary Studies, 24 (1): 101-128.

Martínez Lirola, Maria (2009) Main Processes of Thematization and Potponement in English. Bern: Peter Lang.

Martínez Lirola, María (2011) "An Analysis of Alan Paton as a Discourse of Hope through Cleft Sentences". The buckingham Journal of Language and Linguistics vol. 4: 70-83. Available at: http://www.bjll.org/index.php/bjll/issue/current

Matthiessen, Christian M.I.M., Marvin Lam, Kazuhro Teruya (2010) Key Terms in Systemic Functional Linguistics. London: Continuum.

Nash, Walter. (1980) Designs in Prose. A Study of Compositional Problems and Methods. London: Longman.

Paton. Alan. and Krishna. Shak (1965) Sponono. A Play in Three Acts. New York: Charles Scribner's Sons.

Prince, Ellen. (1984) "Topicalization and Left-Dislocation: A Functional Analysis". In White, Sheila J. and Virginia Teller, eds. Discourses in Reading and Linguistics. New York: The New York Academy of Sciences; 213-225.

Quirk, Randolph, Sidney Greenbaum, Geoffrey Leech and Jan Svartvik (1985) A Comprehensive Grammar of the English Language. London: Longman.

Teubert, Wolfgang (2010) Meaning, Discourse and Society. Cambridge: Cambridge University Press. 